\title{
Electron Microscopy and Computerized Evaluation of Some Partially Denatured Group P Resistance Plasmids
}

\author{
By HANS-JOACHIM BURKARDT, RALF MATTES, * \\ ALFRED PÜHLER AND WOLFRAM HEUMANN \\ Institut für Mikrobiologie und Biochemie, Lehrstuhl für Mikrobiologie der \\ Universität Erlangen-Nürnberg, D-8520 Erlangen, Federal Republic of Germany
}

(Received 18 July 1977; revised 27 September 1977)

DNA of the R plasmids RP1, RP4 and RP8 was isolated from various hosts. The lengths of these plasmid molecules were determined by electron microscopy: RP1 and RP4 were about $19 \mu \mathrm{m}$ long, RP8 measured $31 \mu \mathrm{m}$. An RP4 plasmid mutant, designated RP4a, was isolated from Escherichia coli; it was about $1 \mu \mathrm{m}$ shorter than normal RP4 DNA. To investigate the molecular relationship between RP4, RP4a and RP8, DNAs of these plasmids were partially denatured and examined in the electron microscope. Measurements of the length and denaturation pattern of the DNA molecules were used to construct physical maps. A new computer program was devised for the alignment of the circular molecules, and the effect of variations of different parameters on the reliability of the program was tested. A comparison of the denaturation pattern of RP4 and RP8 indicated that RP8 was composed of total RP4 plus an additional DNA fragment. The RP4a mutant plasmid could be defined as a deletion mutant with loss of $1 \mu \mathrm{m}$ DNA.

\section{INTRODUCTION}

RP plasmids are resistance plasmids which were isolated from pathogenic Pseudomonas aeruginosa strains (Black \& Girdwood, 1969; Lowbury et al., 1969). Because of their origin they are designated as group $\mathbf{P}$ resistance plasmids. They are of particular genetic interest because they possess the widest host range of all known R plasmids (Datta \& Hedges, 1972) and are able to mediate transfer of genetic information between bacterial species (Olsen \& Gonzales, 1974).

The aim of this investigation was to determine the molecular weights of RP1, RP4, RP4a and RP8, isolated from different hosts, by electron microscopical techniques and to investigate the molecular relationship between these plasmids. The designations RP1, RP4, and RP8 were introduced by Holloway \& Richmond (1973); it is still uncertain whether RP1 and RP4 are identical plasmids (because of the identical properties and isolation history of RP4), but RP8 differs from both in its molecular weight. RP4a is a newly isolated mutant derivative of RP4.

To investigate the molecular biology of these plasmids and the relationships between them, several techniques can be used:

1. DNA-DNA hybridization. Such studies were reported by Saunders \& Grinsted (1972) and Holloway \& Richmond (1973) and revealed a homology between RP4 and RP1 of $>85 \%$, and between RP8 and RP1 of $65 \%$.

2. Restriction enzyme cleavage analysis. This type of analysis is difficult with RP

* Present address: Fachbereich Biologie, Lehrstuhl Biologie IX (Genetik), Universität Regensburg, D-84 Regensburg, Federal Republic of Germany. 
Table 1. Bacterial strains

Strain

Escherichia coli NC22(RP8)

E. coli $\mathrm{NC} 22$

E. coli NC22-1

Pseudomonas aeruginosa Ps18(RP1) Rhizobium lupini 1-250(RP4)

R. lupini $1-20$

R. lupini 1-486
Chromosomal markers*

met, leu, thy, rif, nal met, leu, thy, rif, nal

met, leu, thy, rif, nal, str

prototroph

prototroph, car-y

his, car-l

ilv, str, car-y
Origin

M. H. Richmond (Bristol)

A cured (spontaneous loss) single

colony of $E$. coli NC22(RP8)

A streptomycin-resistant mutant of

E. coli $\mathrm{NC} 22$

M. H. Richmond (Bristol)

R. W. Hedges (London), laboratory

stock strain

Laboratory stock strain

Laboratory stock strain

* The genotype symbols designate the following: car- $y$, yellow pigmentation, car-l, white; his, histidine requirement; ilv, isoleucine plus valine requirement; leu, leucine requirement; met, methionine requirement; nal, nalidixic acid resistance; rif, rifampicin resistance; str, streptomycin resistance; thy, thymine requirement.

plasmids because most enzymes have only a few cleavage sites (RP4: Jacob \& Grinter, 1975; J. Grinsted, personal communication).

3. Heteroduplex mapping. RP plasmids are rather large ( $>40 \times 10^{6}$ a.m.u.) and their DNA is much denser $\left(1.719 \mathrm{~g} \mathrm{ml}^{-1}\right)$ than $E$. coli DNA which makes heteroduplex analysis difficult.

4. Physical mapping by partial denaturation analysis. We chose this method, developed by Inman (1966), because it could be easily applied to RP plasmid DNA. By this technique the hydrogen bonds of a double-stranded DNA are weakened (generally by heating or alkalization) until the double helix starts to separate partially into its single strands. The separation occurs preferentially in AT-rich regions. This enables a physical characterization of DNA molecules by their specific denaturation maps which indicate AT-rich regions. The final map is the result of different individual maps for each molecule since, because of experimental conditions, the individual maps of all molecules of one DNA type will differ slightly. Thus a method is required for the best-fitting alignment of these molecules. The coordination can easily be achieved for linear molecules (Gomez \& Lang, 1972) since there are only two possible orientations. There are many possibilities for circularly permuted DNA molecules since there are no fixed starting or ending points in regard to the genetic information of the molecule. Tye, Huberman \& Botstein (1974) have applied a computer program for alignment of such molecules.

This paper describes the evaluation of the results of partial denaturation of the $R$ plasmids RP4, RP4a and RP8 by a new computer program. This computer evaluation is generally applicable for the evaluation of partially denatured circular DNA molecules.

\section{METHODS}

Bacterial strains and plasmids. Details of the strains used are listed in Table 1. The origin and properties of the tested plasmids are listed in Table 2.

Isolation of plasmid DNA. RP plasmid DNA was isolated after cell lysis using sarcosyl according to Bazaral \& Helinski (1968), and centrifugation in a caesium chloride/ethidium bromide density gradient as described by Radloff, Bauer \& Vinograd (1967). For $E$. coli, the DNA was labelled by cultivation in minimal medium containing $\left[{ }^{3} \mathrm{H}\right]$ thymidine $\left(5 \mu \mathrm{Ci} \mathrm{ml}^{-1}\right)$. Fractions were collected from the gradients and those which contained radioactive DNA were identified by liquid scintillation counting. This procedure was not possible for $P$. aeruginosa and $R$. lupini because Thy ${ }^{-}$mutants were not available. Therefore three or four fractions (of about $50 \mu \mathrm{l}$ ) from the region corresponding to that where the E. coli DNA banded were pooled.

Electron microscopy. (i) Standard preparation. Samples were prepared in $0 \cdot 2 \mathrm{M}$-ammonium acetate according to Lang \& Mitani (1970): $0.49 \mathrm{ml}$ of an aqueous solution containing $0.2 \mathrm{M}$-ammonium acetate, $1 \mathrm{~mm}-$ $\mathrm{Na}_{2}$ EDTA, $0.00027 \%(\mathrm{w} / \mathrm{v}$ ) cytochrome $c$ (from horse heart; Serva, Heidelberg, F.R.G.) and $0.2 \%(\mathrm{v} / \mathrm{v}$ ) formaldehyde was mixed with $0.01 \mathrm{ml}$ of DNA-containing fraction. Since no lengths differences could be 
Table 2. Properties and origin of plasmids

\begin{tabular}{ccc} 
Plasmid & Markers* & \multicolumn{1}{c}{ Host } \\
RP1 & amp, kan, tet & P. aeruginosa Ps18(RP1) \\
RP1 & amp, kan, tet & E. coli NC22-1(RP1)
\end{tabular}

RP1 amp, kan, tet R. lupini 1-20(RP1)

RP4 amp, kan, tet R. lupini 1-20(RP4)

RP4 amp, kan, tet E. coli NC22-1(RP4)

RP8 amp, kan, tet E. coli NC22(RP8)
Origin

M. H. Richmond (Bristol)

Cross $P$. aeruginosa $\mathrm{Ps} 18(\mathrm{RP} 1) \times E$. coli $\mathrm{NC22}-1$ on solid medium; $P$. aeruginosa counterselected by streptomycin. RP1 in E. coli tested by m.i.c. (minimal inhibitory concentration) determination and sensitivity in spot test against the RP plasmid-specific phage PRR1 (Olsen \& Thomas, 1973).

Two crosses on solid medium: $P$.aeruginosa Ps18(RP1) $\times R$. lupini $1-486$ and $R$. lupini $1-486(\mathrm{RP} 1) \times R$. lupini 1-20. First, ccunterselection by streptomycin; second, identification of $1-20$ by colour. RP1 in $R$. lupini tested by drug resistance [40 $\mu \mathrm{g}$ kanamycin (ml medium $)^{-1} ; 10 \mu$ g tetracycline (ml medium $)^{-1}$ ]. PRR1 sensitivity not expressed in $R$. lupini.

Cross $R$. lupini $1-250(\mathrm{RP} 4) \times R$. lupini $1-20$ on solid medium; 1-20 identified by colour. RP4 in $R$. lupini 1-20 tested by m.i.c. determination. PRR 1 sensitivity not expressed in $R$. lupini.

Cross $R$. lupini $1-20(\mathrm{RP} 4) \times E$. coli $\mathrm{NC} 22-1$ on solid medium; $R$. lupini counterselected by streptomycin. RP4 in E. coli tested by m.i.c. determination and PRR I sensitivity.

M. H. Richmond (Bristol)

* The abbreviations designate the following: amp, ampicillin resistance; kan, kanamycin resistance; tet, tetracycline resistance.

observed after preparation of DNA with and without dialysis to remove the caesium chloride, undialysed DNA-containing fractions were used for electron microscopical preparations in subsequent experiments. After preparation, the DNA was shadowed by Pt/Ir. Length and molecular weight were determined according to Lang (1970). Electron microscopical magnifications were calibrated by a grating replica (cross-line spacing; Balzers Union AG, Balzers, Liechtenstein), and the enlargement during the evaluation process was calibrated by a test negative.

(ii) Partial denaturation. Before denaturation, the DNA was dialysed against $0.01 \mathrm{M}$-potassium/sodium phosphate buffer ( $\mathrm{pH} \mathrm{7)}$ containing $1 \mathrm{mM}-\mathrm{Na}_{2}$ EDTA. The ratio was about $50 \mu 1$ DNA solution to $500 \mathrm{ml}$ buffer. The DNA concentration of the sample was estimated to be 1 to $10 \mu \mathrm{g} \mathrm{ml}^{-1}$. The buffer was changed after $1 \mathrm{~h}$ and $2 \mathrm{~h}$, and dialysis was then continued overnight. Denaturation was carried out according to Bujard (1970): $0.03 \mathrm{ml}$ of an aqueous solution containing $41.5 \%(\mathrm{v} / \mathrm{v}$ ) dimethyl sulphoxide, $0.07 \mathrm{M}$-potassium/sodium phosphate buffer $(\mathrm{pH} 7), 3.5 \mathrm{mM}-\mathrm{Na}_{2}$ EDTA and $8.6 \%$ formaldehyde was mixed with 0.02 $\mathrm{ml}$ of DNA solution. This mixture was heated to $55^{\circ} \mathrm{C}$ for 16 to $18 \mathrm{~min}$ and then chilled in ice.

The partially denatured DNA was prepared for electron microscopy by the droplet method (Lang \&

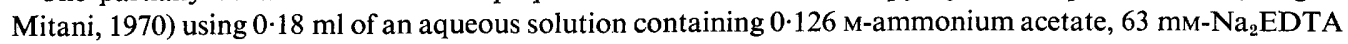
and $0.0003 \%$ cytochrome $c$ mixed with a $0.02 \mathrm{ml}$ sample of partially denatured DNA. The native segments were measured according to Lang (1970). Denatured segments were determined by measuring the circumference of the single-stranded denaturation bubble (i.e. the lengths of the single-stranded branches were summed) and taking half the sum as the probable length of the loop. For further evaluation, a new computer program was developed since the method of Gomez \& Lang (1972) could not be applied to the partially denatured molecules.

\section{RESULTS}

\section{Molecular weight determination}

Host cells are known to modify the molecular structure of plasmids. Therefore, the DNA of the RP plasmids was examined after isolation from different hosts. Electron micrographs of RP1 and RP8 are shown in Figs 1 and 2. At $0 \cdot 2$ cationic strength the correlation of molecular weight/contour length is 207 a.m.u. $/ 10^{-8} \mathrm{~cm}$ (Lang, 1970). This factor was used to calculate the molecular weights of the RP plasmids; these are shown in Table 3 together 


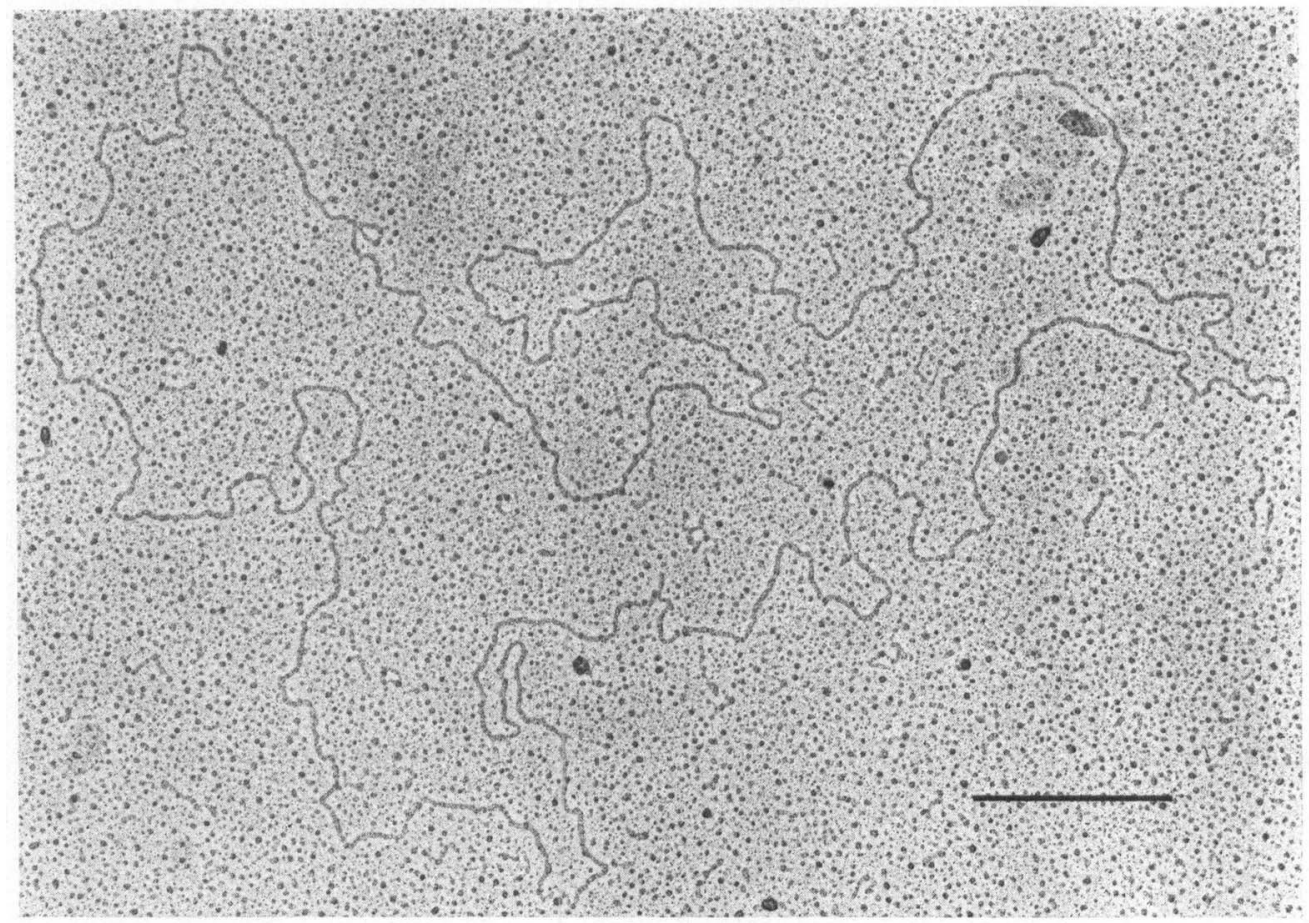

Fig. 1. Open circular RP1 DNA. Bar marker represents $0.5 \mu \mathrm{m}$.

with their mean contour lengths, ranges of length and standard deviations. Length distributions of RP1 plasmid DNA from different hosts are shown in Fig. 3.

Two RP4 plasmids of different length were isolated from $E$. coli in independent experiments (Table 3, Fig. 4). The larger one, which is identical with RP4 from $R$. lupini, is called RP4; the shorter one is RP4a. RP4a emerged spontaneously and was found in only one plasmid isolation. The deletion in RP4a compared with RP4 is indicated not only by length measurements but also by partial denaturation experiments (see below). Occasionally, some molecules with about twice the usual length were found; these could not be divided into two halves at crossing-points and are therefore regarded as dimeric RP plasmids.

\section{Partial denaturation}

A partially denatured RP8 plasmid molecule is shown in Fig. 5, the arrows indicating the denaturation loops. The lengths of these small loops could be measured quite accurately, as the electron micrograph plate was enlarged $\times 16$ for evaluation. The number of loops varied from 0 to 14 in one sample. Two characteristics of the partially denatured molecules rendered the construction of an AT map difficult. (i) RP molecules remained as circular structures after partial denaturation; thus starting or ending points of the molecules could not be defined. (ii) Our denaturation conditions produced only a few small loops in relatively long molecules. It was therefore difficult to arrange the loops in a definite order by visual inspection alone.

\section{Computer program for the construction of AT maps of the circular denatured RP molecules}

A modified version of the program developed for partially denatured SV 40 DNA molecules (Mayer, Mazaitis \& Pühler, 1975) and later applied to circular DNA from mitochondria of Neurospora crassa (Bernard et al., 1975) was used. The unit lengths in $\mathrm{mm}$ of native 


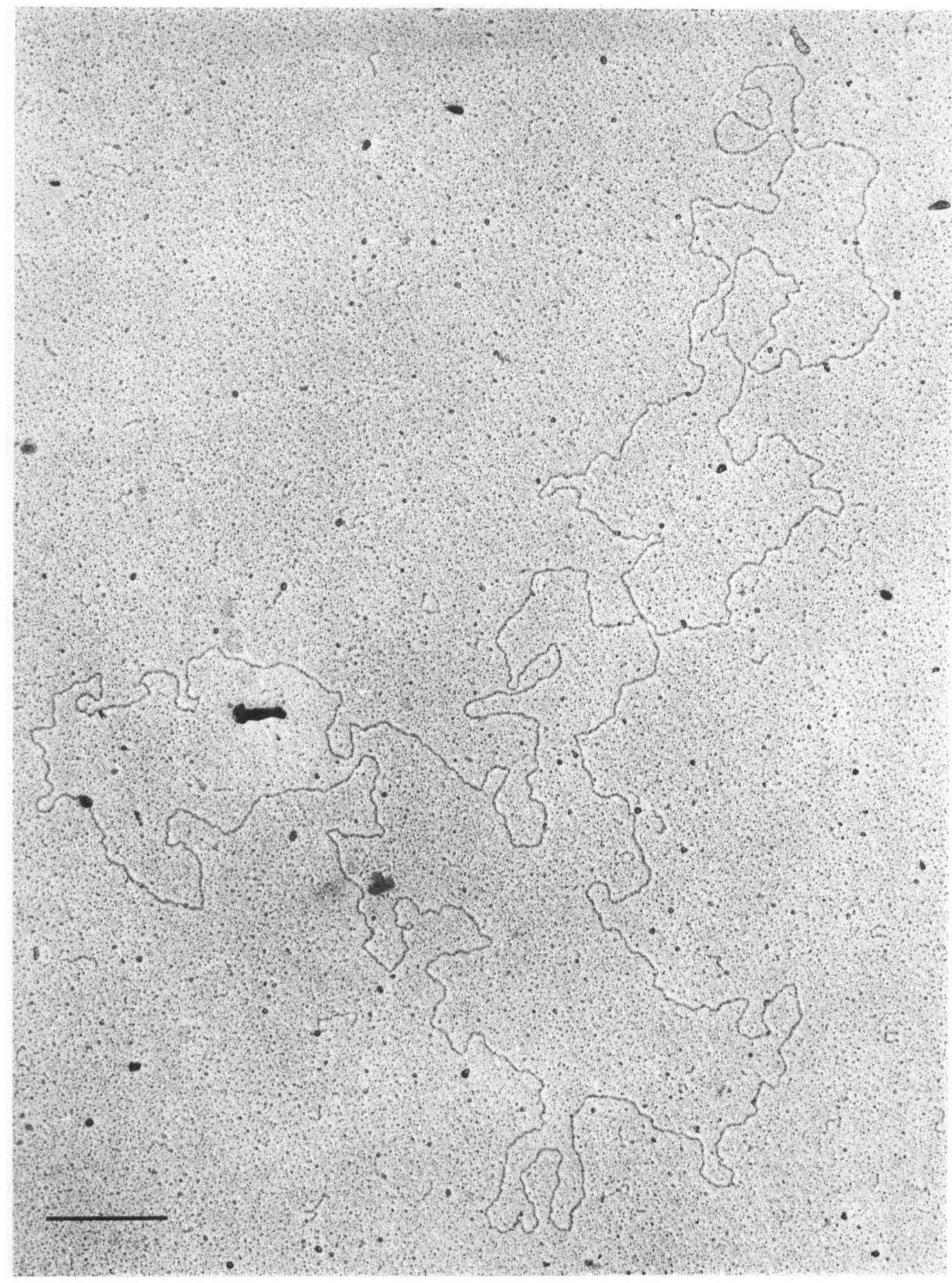

Fig. 2. Open circular RP8 DNA. Bar marker represents $0 \cdot 5 \mu \mathrm{m}$. 
Table 3. Contour length measurements of circular DNA molecules isolated from E. coli, $P$. aeruginosa and $R$. lupini host strains harbouring various $R P$ plasmids

\begin{tabular}{|c|c|c|c|c|c|c|}
\hline Plasmid & Strain & $\begin{array}{l}\text { No. of } \\
\text { molecules } \\
\text { measured }\end{array}$ & $\begin{array}{c}\text { MCL } \pm \text { SSD } * \\
(\mu \mathrm{m})\end{array}$ & $\begin{array}{l}\text { Range of lengths } \\
\qquad(\mu \mathrm{m})\end{array}$ & $\begin{array}{l}\mathrm{SSD} \text { as } \\
\% \mathrm{MCL}\end{array}$ & $\begin{array}{l}10^{-6} \times \\
\text { Mol. wt } \dagger \\
\text { (a.m.u.) }\end{array}$ \\
\hline $\begin{array}{l}\text { RP1 } \\
\text { RP8 } \\
\text { RP4 } \\
\text { RP4a }\end{array}$ & $\begin{array}{l}\text { E. coli } \\
\text { E. coli } \\
\text { E. coli } \\
\text { E. coli }\end{array}$ & $\begin{array}{l}24 \\
26 \\
22 \\
25\end{array}$ & $\begin{array}{l}18.9 \pm 0.4 \\
31 \cdot 3 \pm 0.6 \\
19 \cdot 1 \pm 0.3 \\
17.9 \pm 0.5\end{array}$ & $\begin{array}{l}18 \cdot 1-19 \cdot 7 \\
30 \cdot 0-32 \cdot 8 \\
18 \cdot 5-19 \cdot 4 \\
17 \cdot 2-18 \cdot 8\end{array}$ & $\begin{array}{l}2 \cdot 1 \\
1 \cdot 9 \\
1 \cdot 4 \\
2 \cdot 6\end{array}$ & $\begin{array}{l}39 \\
65 \\
39 \\
37\end{array}$ \\
\hline RP1 & $P$. aeruginosa & 24 & $18 \cdot 8 \pm 0 \cdot 4$ & $18 \cdot 1-19 \cdot 7$ & $2 \cdot 1$ & 39 \\
\hline $\begin{array}{l}\text { RP1 } \\
\text { RP4 }\end{array}$ & $\begin{array}{l}\text { R. lupini } \\
R . \text { lupini }\end{array}$ & $\begin{array}{l}26 \\
24\end{array}$ & $\begin{array}{l}18 \cdot 7 \pm 0 \cdot 1 \\
18 \cdot 5 \pm 0 \cdot 4\end{array}$ & $\begin{array}{l}18 \cdot 1-20 \cdot 3 \\
17 \cdot 6-19 \cdot 1\end{array}$ & $\begin{array}{l}1 \cdot 0 \\
2 \cdot 0\end{array}$ & $\begin{array}{l}39 \\
38\end{array}$ \\
\hline $\begin{array}{l}\text { RP4(d) }+ \\
\text { RP4a(d) } \dagger \\
\text { RP4(d) } \$\end{array}$ & $\begin{array}{l}E . \text { coli } \\
E . \text { coli } \\
R . \text { lupini }\end{array}$ & $\begin{array}{l}1 \\
1 \\
1\end{array}$ & $\begin{array}{l}38 \cdot 2 \\
35 \cdot 0 \\
36 \cdot 6\end{array}$ & - & - & $\begin{array}{l}79 \\
73 \\
76\end{array}$ \\
\hline
\end{tabular}

* MCL, Mean contour length; SSD, sample standard deviation.

$\dagger$ Molecular weight calculated on the assumption that $1 \mathrm{~cm}$ DNA $=207 \times 10^{8}$ a.m.u. (Lang, 1970).

$\ddagger$ (d), Dimeric plasmids.

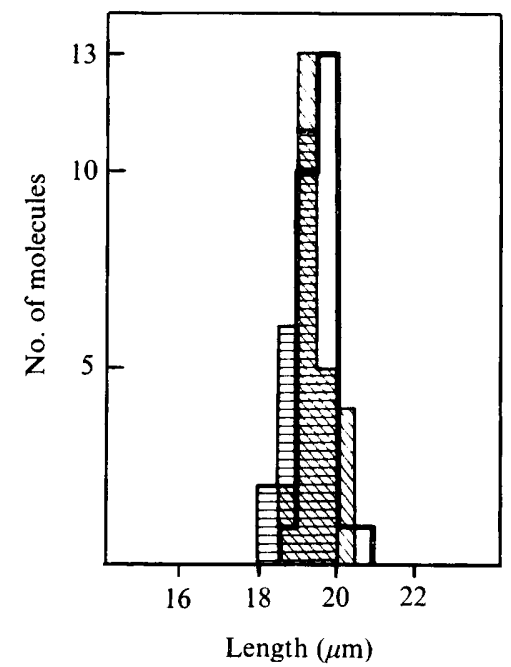

Fig. 3

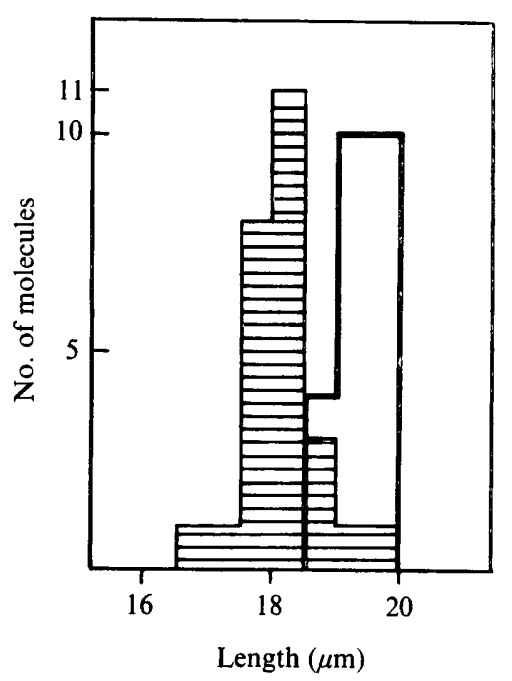

Fig. 4

Fig. 3. Length distribution of RP1 DNA from $E$. coli (horizontal-hatched), $P$. aeruginosa (crosshatched) and $R$. lupini (thick outline).

Fig. 4. Length distribution of RP4 (thick outline) and RP4a (horizontal-hatched) DNA from E. coli.

and denatured regions were fed into the computer alternately. The lengths of the singlestranded regions were not corrected as proposed by Bujard (1970), as, in general, the loop size was very small compared with the whole double-stranded molecule and was mathematically enlarged during the computer evaluation (see below).

The computer program consists of six steps:

1. The entire set of single lengths is summed. This additive dimension is the molecule length after electron microscopical magnification and plate enlargement during the evaluation process. The real molecule length is defined by division of this length by the enlargement factor [composed of the electron microscopical magnification and the plate magnification $(\times 16)]$. 


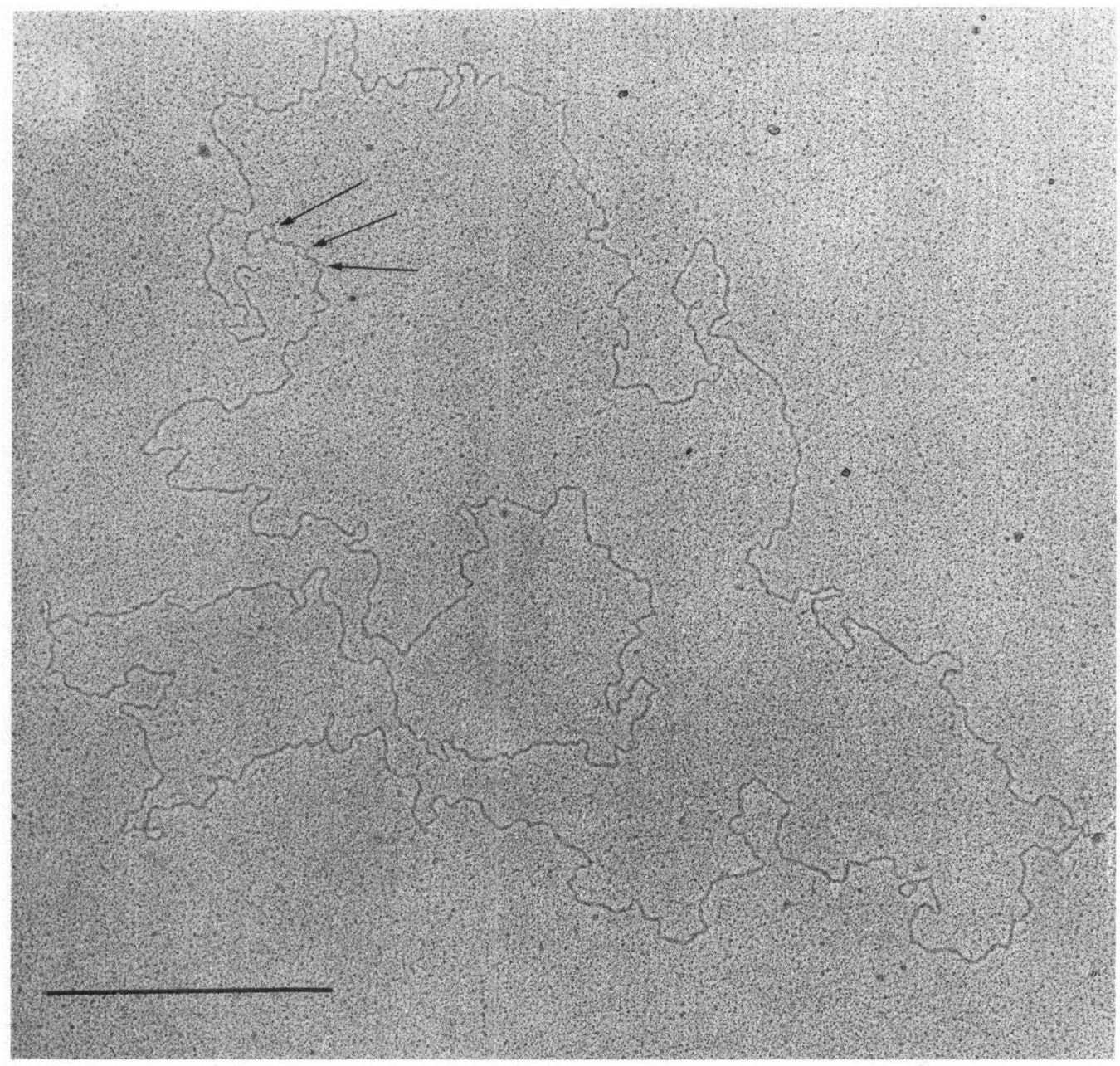

Fig. 5. Partially denatured RP8 DNA. All sites of partial denaturation are marked by arrows. The loops are clearer at the higher magnification used during evaluation. Bar marker represents $1.0 \mu \mathrm{m}$.

2. A standard molecule with a length of $100 \%$ is defined by the mean length of all molecules. Each molecule is stretched or shortened to fit the standard. Elimination of extremely long or short measurements (deviation $\geqslant 5 \%$ ) did not improve the map.

3. All loops are enlarged to a unit length of 1,2 or $3 \%$ of the molecule size. A minimal enlargement of $1 \%$ is necessary since most of the loops produced experimentally are smaller than the resolving power of the computer (1\% of molecule length). A map with $1 \%$ enlargement is shown in Fig. 6(a). Further enlargements of 2 and $3 \%$ (Figs $6 b$ and $c$ ) make the denaturation pattern coarse but more distinct, as those loops which are misplaced by preparation artefacts (such as DNA stretching or shortening by coiling) may be correctly ordered. A comparison of the denaturation maps in Fig. 6 indicates the improvement of the loop order by increasing the loop size from 1 to $3 \%$ of the molecule length.

4. The molecules are printed according to the sequence of denatured and native regions. They are subdivided into segments, the size of which depends upon the program and the capacity of the computer: in our case, $1 \%$ of the molecule standard length. The computer prints a specific sign for each denatured or native segment respectively.

5. The computer arranges the molecules according to their maximum conformity of all sites. The sequence of the molecules to be fed into the computer is very important for the 

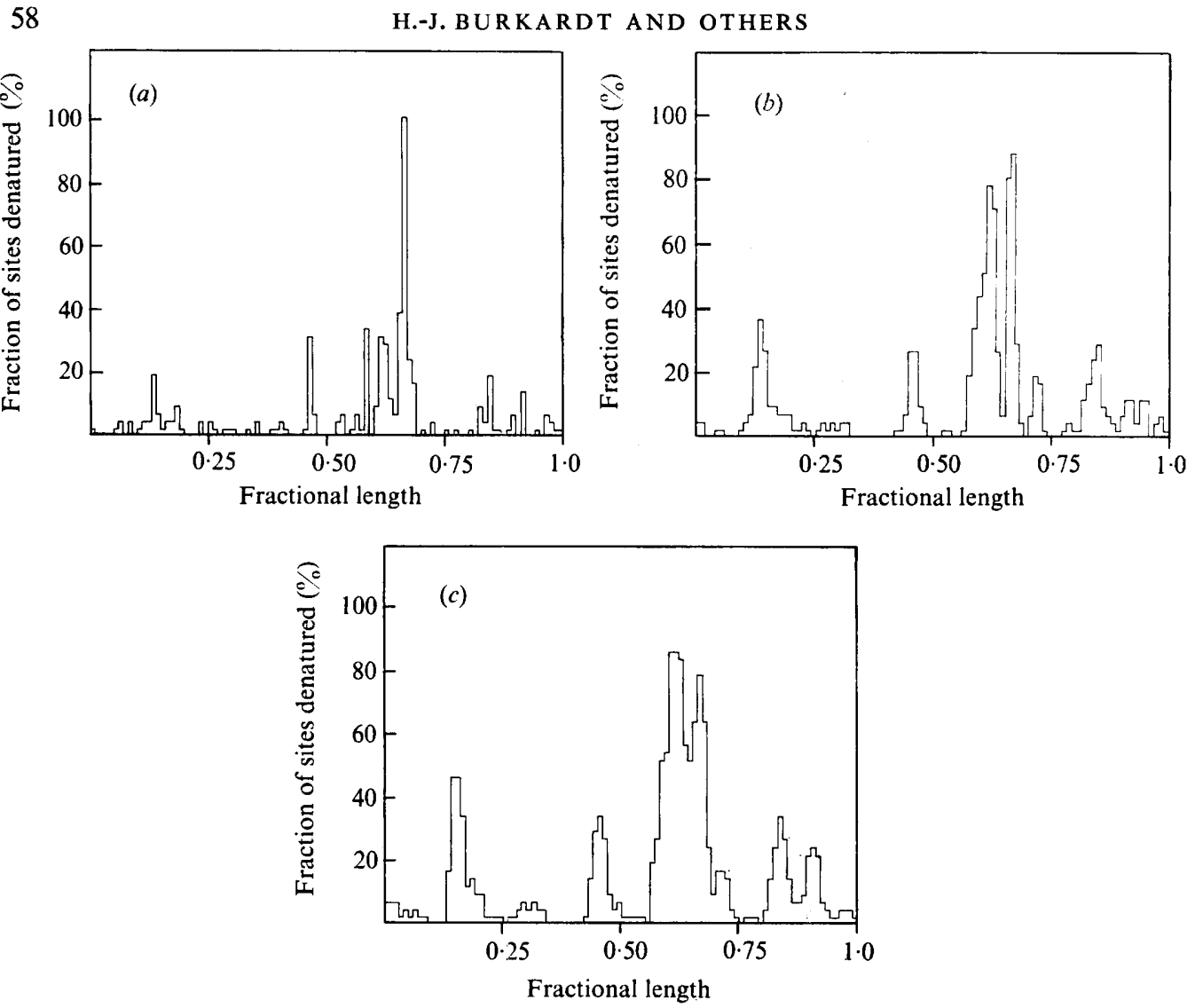

Fig. 6. Maps of partial denaturation of RP4 DNA (43 molecules measured). Standard lengths of loops (relative to the total molecule length): (a) $1 \%$; (b) $2 \% ;(c) 3 \%$.

construction of an AT map. The computer orders the molecules by trial and error by superimposing and moving two molecules until it achieves maximum conformity, i.e. the largest amount of congruence of native and denatured sites. It then constructs the resultant molecule of the two (because they have small differences) and arranges the third molecule according to the resultant pattern. A reasonable sequence is as follows: the first molecule is that with the most distinctive denaturation pattern, i.e. with the highest loop number and the smallest loops; the next is the one with larger denatured regions and/or one loop less etc.

6. The segments of identical molecule sites are summed. One denatured segment will be read as a unit in the direction of the abscissa in the diagram.

\section{Comparison of the AT maps of RP4, RP8 and RP4a}

$R P 4$ and RP8. The map of RP8 in Fig. 7 has been enlarged $(\times 1.6)$ because the contour length of RP8 $(31 \mu \mathrm{m})$ is $1 \cdot 6$-fold longer than that of RP4 $(19 \mu \mathrm{m})$ and the computer prints the maps at equal length. Comparison of the maps shows that a large region of RP8 is identical with the entire but smaller RP4. There are, however, some slight differences between the maps. In our opinion these differences do not reflect actual molecular differences but can be explained by experimental and evaluation procedures (see Discussion). Thus RP8 DNA comprises the complete DNA of RP4 as one sequence and an additional segment of DNA.

RP4 and RP4a. Comparison of the AT maps of the RP4 and RP4a plasmids after arrangement of the two denaturation profiles to maximum conformity (Fig. 8) indicates the probable site and length of the deletion in RP4a. 


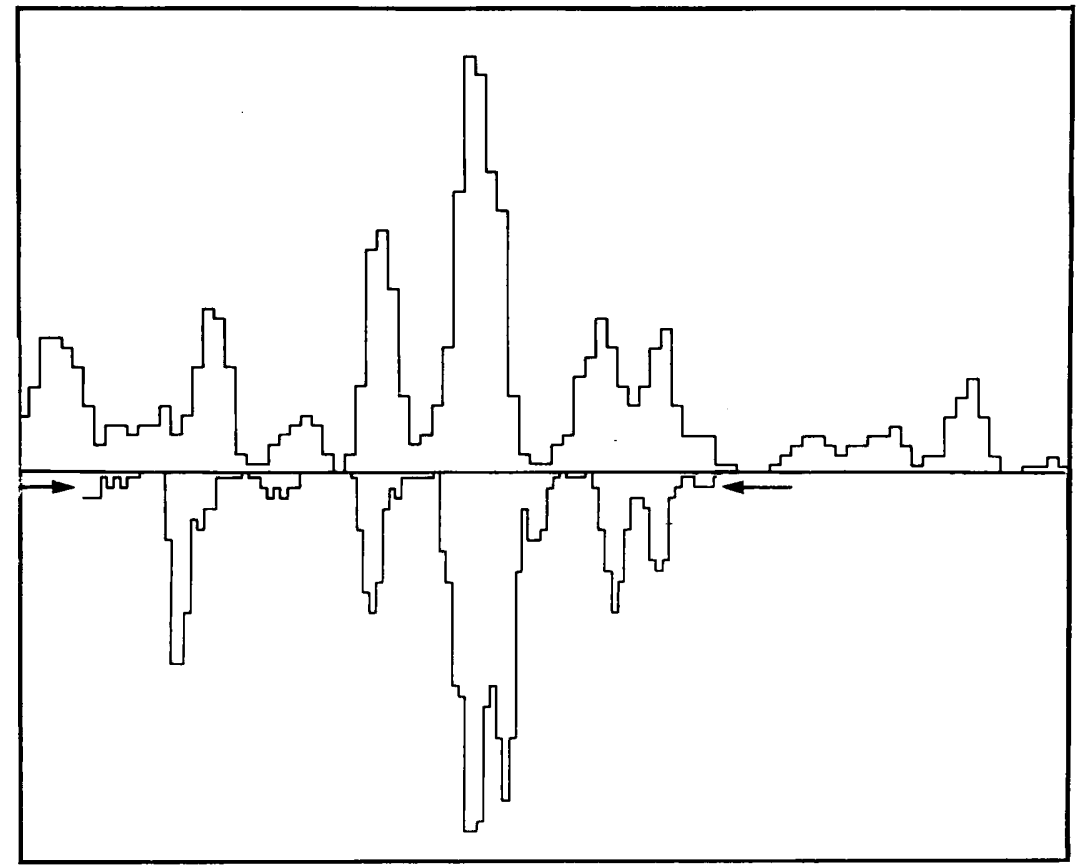

Fig. 7. Comparison of partial denaturation patterns of RP8 (above) and RP4 (below). The end points of RP4 are marked by arrows. The positions of the peaks are more important than their shapes - see text.

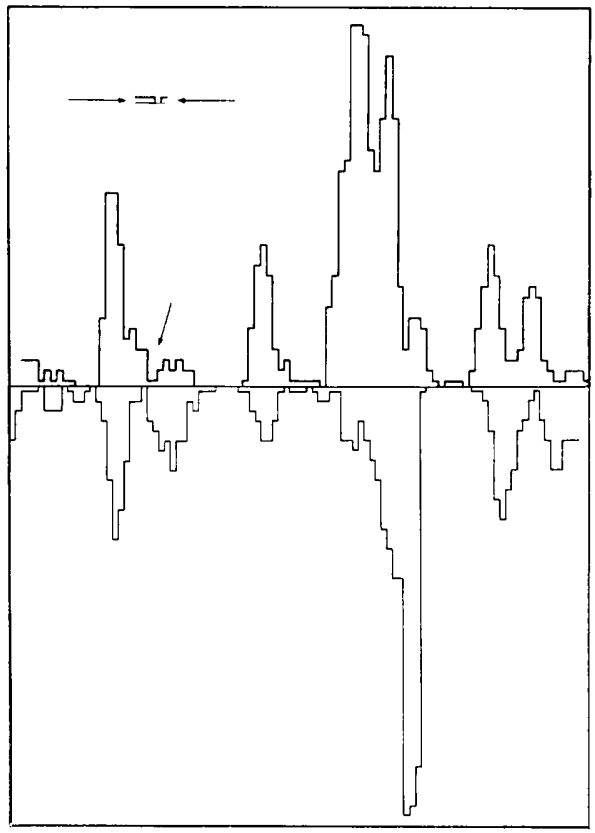

Fig. 8. Comparison of partial denaturation patterns of RP4 (above) and RP4a (below). The presumed deletion site and DNA fragment cut out are marked by arrows. The positions of the peaks are more important than their shapes - see text. 

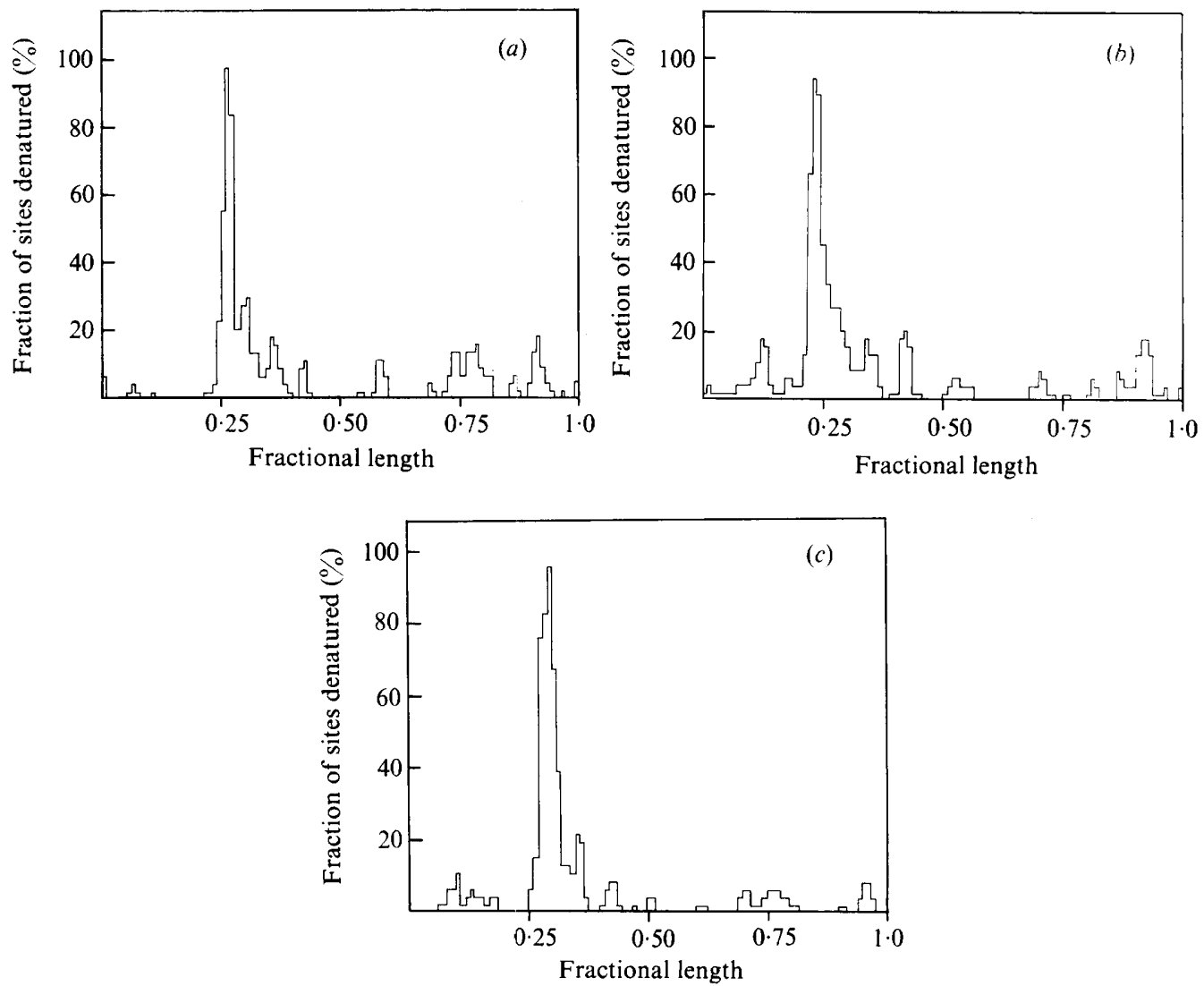

Fig. 9. Maps of partial denaturation of segments of (a) RP4 (10\% of total length of molecule), (b) RP4a (10\% of total length of molecule) and (c) RP8 (6\% of total length of molecule).

\section{Fine-structure maps of AT-rich regions}

In the evaluation of the denaturation pattern of entire molecules the localization of the loops has been defined without reference to their sizes. For fine-structure mapping of highly structured segments, these segments were enlarged until all loops, even the small ones, could be resolved and arranged by the computer. For a detailed comparison of the AT maps of the three plasmids RP4, RP4a and RP8, the segment of the most prominent peak of each AT map was selected and fed into the computer. The sizes of these segments were $10 \%$ of RP4 and RP4a, and 6\% of RP8 respectively. A comparison of $t$ he three maps (Fig. 9), further indicates the close relationship of these three plasmids.

\section{DISCUSSION}

Molecular weight determination. Our values for the molecular weights of RP plasmids obtained by electron microscopy agree with those obtained previously by sedimentation analysis (Grinsted et al., 1972; Saunders \& Grinsted, 1972). The RP plasmids are apparently quite stable in the hosts tested. The RP1 DNA is identical in $E$. coli, $P$. aeruginosa and $R$. lupini. The RP plasmid RP4a had a $1 \mu \mathrm{m}$ deletion compared with the normal RP4 from $E$. coli and $R$. lupini and RP1 from E. coli, P. aeriginosa and R. lupini, and so its molecular weight is lower than that of the RP4 plasmid described previously (Holloway \& Richmond, 1973). The $1 \mu \mathrm{m}$ deletion was confirmed by partial denaturation of RP4 and RP4a DNA (see below). Shortened RP4 factors have also been detected after segregation into $R$. lupini minicells (Tucher, 1974). 
Dimer formation of RP plasmids is apparently a rare event. The frequency of observed dimers was less than $1 \%$ in both $E$. coli and $R$. lupini.

Partial denaturation. The number and sizes of the loops produced by our denaturation technique are relatively small. The reason for this might be the relatively high GC content of RP DNA molecules $(60 \%)$. Higher denaturation temperatures resulted in coil formation of the DNA. The number of loops could, however, be increased by holding the DNA in denaturation solution at room temperature for more than a week (Mayer et al., 1975). Despite the small amount of denaturation, our computer program enabled us to use this plasmid characteristic for the construction of reliable AT maps. The small number of loops increased the precision of the maps.

The computer program. The artificial enlargement of the loops up to $3 \%$ of the plasmid length improves the accuracy of their computerized order without producing new peaks. This was confirmed by maps which were constructed after elimination of molecules with extreme deviations in length. The latter must have been artefacts, as the plasmids generally have a fairly constant length (Table 3 ). Thus some loops are presumably misplaced and may disturb the true pattern. A comparison of the maps, with and without elimination, at $3 \%$ loop magnification showed only slight differences, so our program produced an accurate arrangement even in the presence of these disturbing molecules.

Comparison of the homology of RP4, RP8 and RP4a by the denaturation pattern of their AT maps. ( $i$ ) RP4 and RP8. The RP8 molecule is composed of RP4 plus an additional DNA fragment. The slight differences between the AT map of RP4 and the relevant section of the RP8 map (Fig. 7) can be explained on technical grounds. Firstly, the resolution of the RP4 map is, in general, better than that of RP8. This can be explained by the different lengths of the molecules at the same resolving power of the computer: the map of RP4 is more distinct than that of RP8, as RP4 is shorter than RP8. This may also explain the different shapes of the main peaks. Secondly, the slight differences in the peak positions are almost certainly due to the procedure of normalizing the molecule lengths to fit in the hypothetical standard molecule.

The degree of similarity between the two plasmids is in good agreement with the hybridization results [RP8 hybridizes to 65\% with RP1 (Saunders \& Grinsted, 1972); RP1 is very similar to RP4 according to Holloway \& Richmond (1973)]. The additional DNA of RP8 contains neither the region coding for drug resistance nor the transfer genes, since all these are localized on the segment which is homologous to RP4. It does, however, confer a higher host specificity on RP8 since, unlike RP4, this plasmid cannot be transferred to R. lupini (unpublished results).

(ii) RP4 and RP4a. Comparison of the AT maps of these plasmids reveals a deletion in the RP4a molecule (Fig. 8). There are some differences between the maps to the right of the main peak, but we consider that these have no real relevance and are due to variations in the method. For the localization of the deletion, it is only important that one achieves a greater congruence of both maps after cutting a $1 \mu \mathrm{m}$ piece out of the map of the RP4 plasmid at one specific point. The deletion does not influence the known resistance and transfer characteristics of the RP4a plasmid.

Fine structure mapping. For this, the loop size was not standardized; instead the actual size and number of loops of the most structured DNA segment were evaluated. A segment $2 \mu \mathrm{m}$ long was selected by the computer. The resolution of the program was enhanced about 10 times and loops as small as $0.02 \mu \mathrm{m}$ could be discerned. According to Inman (1966) this is the minimal loop size which will be relevant in denaturation experiments. The fine structure maps of the three plasmids resolve the main AT peak of their coarse structure maps. The three adjacent AT peaks between fractional lengths 0.25 and 0.45 (Fig. 9) correspond to the three loops in Fig. 5. In these three maps the size of the most prominent AT peak is probably an artefact, since the computer orders all the selected segments with only 
one loop into this position. Despite this, comparison of the fine structure maps of the three plasmids shows their similarity.

The methods of coarse and fine mapping are suitable for specific characterization of plasmid molecules and have allowed us to investigate the molecular relationship of the RP plasmids. A restriction enzyme analysis of these plasmids is difficult because most enzymes have only a few cleavage sites (J.Grinsted, personal communication). Heteroduplex analysis, by which the present results could be confirmed, will be done in the future.

We thank Dr M. H. Richmond for the bacterial strains E. coli $\mathrm{NC} 22(\mathrm{RP} 8)$ and P. aeruginosa Ps 18(RP1), Dr R. W. Hedges for the strain $R$. lupini 1-250(RP4) and Dr H. Olsen for the phage PRR1. We are also indebted to Dr F. Mayer for instruction in electron microscopical DNA preparation techniques, Dr J. Beringer for critical reading of the manuscript and Mrs B. Görg for technical assistance. One of us (R.M.) was sponsored by 'Studienstiftung des deutschen Volkes'. This research was supported by Deutsche Forschungsgemeinschaft.

\section{REFERENCES}

Bazaral, M. \& Helinski, D. R. (1968). Characterization of multiple circular DNA forms of colicinogenic factor E1 from Proteus mirabilis. Biochemistry 7, 3513-3519.

Bernard, U., Pühler, A., Mayer, F. \& Küntzel, H. (1975). Denaturation map of the circular mitochondrial genome of Neurospora crassa. Biochimica et biophysica acta 402, 270-278.

Black, W. A. \& Girdwood, R. W. A. (1969). Carbenicillin resistance in Pseudomonas aeruginosa. British Medical Journal iv, 234.

Bujard, H. (1970). Electron microscopy of singlestranded DNA. Journal of Molecular Biology 49, 125-137.

DatTA, N. \& Hedges, R. W. (1972). Host ranges of $\mathrm{R}$ factors. Journal of General Microbiology $\mathbf{7 0}$, 453-460.

Gomez, B. \& LANG, D. (1972). Denaturation map of bacteriophage T7 DNA and direction of DNA transcription. Journal of Molecular Biology 70, 239-251.

Grinsted, J., SAunders, J. R., Ingram, L. C., Sykes, R. B. \& Richmond, M. H. (1972). Properties of an $\mathbf{R}$ factor which originated in Pseudomonas aeruginosa 1822. Journal of Bacteriology 110, 529-537.

Holloway, B. W. \& Richmond, M. H. (1973). $\mathbf{R}$ factors used for genetic studies in strains of Pseudomonas aeruginosa and their origin. Genetical Research, Cambridge 21, 103-105.

InMAN, R. B. (1966). A denaturation map of the $\lambda$ phage DNA molecule determined by electron microscopy. Journal of Molecular Biology 18, 464-476.

JACOB, A. E. \& Grinter, N. J. (1975). Plasmid RP4 as a vector replicon in genetic engineering. Nature, London 255, 504-506.

LANG, D. (1970). Molecular weight of coliphages and coliphage DNA. III. Contour length and molecular weight of DNA from bacteriophages $\mathrm{T} 4, \mathrm{~T} 5$ and $\mathrm{T} 7$, and from bovine papilloma virus. Journal of Molecular Biology 54, 557-565.
LanG, D. \& Mitani, M. (1970). Simplified quantitative electron microscopy of biopolymers. Biopolymers 9, 373-379.

Lowbury, E. J. L., Kinson, A., Lilly, H. A., Ayliffe, G. A. \& Jones, R. J. (1969). Sensitivity of Pseudomonas aeruginosa to antibiotics: emergence of strains highly resistant to carbenicillin. Lancet ii, 448-452.

Mayer, F., Mazaitis, A. J. \& Pühler, A. (1975). Electron microscopy of Simian Virus 40 DNA configuration under denaturation conditions. Journal of Virology 15, 585-598.

Olsen, R. H. \& Gonzales, C. (1974). Escherichia coli gene transfer to unrelated bacteria by a histidine operon-RP1 drug resistance plasmid complex. Biochemical and Biophysical Research Communications 59, 377-385.

Olsen, R. H. \& Thomas, D. D. (1973). Characteristics and purification of PRR1, an RNA phage specific for the broad host range Pseudomonas R1822 drug resistance plasmid. Journal of Virology 12, 1560-1567.

Radloff, R., Bauer, W. \& Vinograd, J. (1967). A dye-buoyant-density method for the detection and isolation of closed circular duplex DNA. The closed circular DNA in HeLa cells. Proceedings of the National Academy of Sciences of the United States of America 57, 1514-1521.

Saunders, J. \& Grinsted, J. (1972). Properties of RP4 an $\mathbf{R}$ factor which originated in Pseudomonas aeruginosa $\mathrm{s} 8$. Journal of Bacteriology 112, 690-696.

TUCHER, R. (1974). Untersuchungen an RP4-DNA in Minizellen von Rhizobium lupini. Thesis, Universität Erlangen-Nürnberg, Federal Republic of Germany.

Tye, B.-K., Huberman, J. A. \& Botstein, D. (1974). Non-random circular permutation of phage P22 DNA. Journal of Molecular Biology 85, 501-523. 